\title{
Factors Influencing Tax Stamp Purchases in Ghana: A Case of Twifo-Atti Morkwa Sub-tax District
}

\section{Adu KO ${ }^{1 *}$ and Amponsah $\mathrm{S}^{2}$}

${ }^{1}$ Department of Economics, University of Cape Coast, Ghana

${ }^{2}$ Department of Accounting and Finance, School of Business, University of Cape Coast, Ghana

\begin{abstract}
This study examined the factors that influence the number of tax stump purchased in Twifo-AttiMorkwa sub-tax district in Ghana. Data were collected from taxpayers in the study area who qualify for tax stamps using the interview schedule. In total, 305 taxpayers were interviewed. The study employed negative binomial regression model to examine the factors that influence the quantity of tax stamp purchased. It was found that the taxpayer's level of education, the perceived importance he/she attaches to tax payment, guilt feelings and other tax administration factors, including the application of sanctions, the rate of tax audit and distance to tax office were key predictors of tax stamp purchases. This study, therefore, recommends that tax auditors should go round at least at the beginning of every quarter to inspect the number of tax stamps that taxpayers have bought. The study also recommends that Ghana Revenue Authority should apply sanctions promptly when taxpayers default payment.
\end{abstract}

Keywords: Tax stamp; Taxpayers; Negative binomial model

\section{Introduction}

Taxes play a major role in the development of a country. They are a major source of government revenue in developing countries, including Ghana. Tax revenue is used for financing government or public expenditure. Taxes are collected from both the formal sector and the informal sector [1]. The informal sector provides about 86 percent of the total employment in Ghana. According to Asante and Baba [2] the sector has the greatest potential to raise tax revenue from employment as compared to the formal sector. However, it has been noted that out of the 1.5 million Ghanaians who are legally required to pay direct taxes, only 5 percent of them come from the informal sector [3].

In an attempt to improve on tax collections from the informal sector, the Tax Stamp System (TSS) was introduced by the Internal Revenue (Amendment) Regulations, 2004, (LI 1803). The main purpose for the enactment was to enhance easy identification of small scale self-employed persons in the informal sector in Ghana. Following the introduction of this Regulation, persons operating in kiosks, on table tops, identifiable groups such as hairdressers, dressmakers and tailors, butchers, market traders, chop bar and cooked food sellers, artisans such as masons, carpenters, welders, mechanics, among others were identified and included in the tax bracket. Most of these taxpayers are females.

The new tax Regulation categorised taxable persons from the informal sector into two: by business type and by volume of business operations. The Regulation also imposes an obligation on taxpayers to buy the tax stamp in advance (i.e. $15^{\text {th }}$ January, $15^{\text {th }}$ April, $15^{\text {th }}$ July and $15^{\text {th }}$ October), and to conspicuously display the tax stamp on their business premises. Like any system for tax collection, punitive measures were put in place to enforce compliance by the Internal Revenue Service (now the Ghana Revenue Authority (GRA), 2009 (Act 791) at the district level. It must be noted that unlike the other types of tax which are imposed on profit or the income earned by taxpayers, the tax stamp levy is assessed on the basis of the size and volume of the taxpayer's business. Though the introduction of tax stamp in Ghana had impacted positively on self employed tax collections, it is found to be characterised by high level of tax evasion [4].
Following a study on "Determinants of Tax Stamp Evasion at Twifo Atti-Morkwa Sub-Tax District" by Amponsah [4], it was found that most studies on tax evasion in the Ghanaian informal sector have focused mainly on taxpayers who are assessed on the basis of the profits they make, thereby ignoring taxpayers who ought to have been taxed in accordance to the level of their business operations (size of business). Using the binary logic, the author identified the broad determinants of tax evasion without explaining the intensity of tax stamp purchased in his study area. In other words, the author could only list the factors that determine tax stamp evasion in the study area. A critical observation of this study revealed that the author failed to analyse the extent to which each factor influenced the number of tax stamp purchased by tax payers. It is this gap that has created the platform for this current study.

The authors in this current study observed that the analytical tool (binary log it) used by Amponsah [4] failed to help him analyse the extent to which each factor influenced the number of tax stamp purchased by taxpayers. In their opinion, the generalised model for estimating a count variable (in this case tax stamp purchases) is the Poisson regression. Poisson regression treats the number of tax stamp purchased as a Poisson random variable with an intensity hypothesised to depend on posited explanatory variables [5]. In Poisson regression, there is an assumption of equality of the conditional mean and variance functions. This assumption is typically taken to be the major drawback of the Poisson regression model. In order to overcome this shortcoming in this study, the negative binomial regression, which arises from a natural formulation of cross-section heterogeneity, was adopted [5]. The negative binomial model is more general than Poisson since it caters for over dispersion of subjects in a study.

*Corresponding author: Adu KO, Department of Economics, University of Cape Coast, Ghana, Tel: +233242388459; E-mail: Kofi.adu@stu.ucc.edu.gh

Received May 06, 2016; Accepted May 12, 2016; Published May 19, 2016

Citation: Adu KO, Amponsah S (2016) Factors Influencing Tax Stamp Purchases in Ghana: A Case of Twifo-Atti Morkwa Sub-tax District. J Account Mark 5: 175 doi:10.4172/2168-9601.1000175

Copyright: ( 2016 Adu KO, et al. This is an open-access article distributed under the terms of the Creative Commons Attribution License, which permits unrestricted use, distribution, and reproduction in any medium, provided the original author and source are credited. 
The general objective of this study was to analyse the factors that influence the number of tax stamp purchased at Twifo-AttiMorkwa Sub-Tax District. The specific objectives of the study were to:

1. Examine the socio-economic factors that influence the number of tax stamp purchased:

2. Determine the effect of guilt feeling on the number of tax stamp purchased:

3. Determine the effect of distance between taxpayers' place of business and tax office on the number of tax stamp purchased.

In order to achieve the specific objectives, the following hypotheses were formulated.

1. $\mathrm{H}_{0}$ : Socio-economic factors do not affect the number of tax stamp purchased.

$\mathrm{H}_{1}$ : Socio-economic factors affect the number of tax stamp purchased.

2. $\mathrm{H}_{0}$ : Guilt feeling has no effect on the number of tax stamp purchased.

$\mathrm{H}_{1}$ : Guilt feeling has effect on the number of tax stamp purchased.

3. $\mathrm{H}_{0}$ : Distance between taxpayer's place of business and tax office has no effect on the number of tax stamp purchased.

$\mathrm{H}_{1}$ : Distance between taxpayer's place of business and tax office has effect on the number of tax stamp purchased.

\section{Literature Review}

Tax evasion is explained by a mix of economic, demographical, psychological, and additional factors [6,7]. A review of literature on these factors in relation to tax evasion and its influence on the number of tax stamp purchases is provided in this section. The factors that are relevant in this study include demographic (gender, age and education), economic (rate of tax audit and sanctions), psychological (guilt feeling) and perceptions.

\section{Gender and tax evasion}

Kedir et al. [8] evaluated one kind of tax evasion (an unofficial 'envelope' wage) in the European Union. In all, they examined a database made up of 26,659 through a face-to-face interview in the 27 member states. They also used unordered and ordered discrete models as well as interval regression as their analytical tools. Among their control variables was gender of the respondent. The authors tested the significance of the predictors at ten percent (10\%), five percent $(5 \%)$, and one percent (1\%) levels of significance. Both the ordered and the interval regression estimates showed a positive significant relationship between male and tax evasion (under declared activity). They attributed the positive coefficient of male to the notion that males are globally known to show low tax morale.

The study of Mcgee and Ross [9] also shows the relationship between gender and tax evasion, using data that was gathered by social scientists in Brazil, Russia, India, China, the USA and Germany, and a 10 point Likert Scale to find the relationship between gender and attitudes towards tax evasion. Apart from United States where the study found women to be definitely and consistently more strongly opposed to tax evasion, results in the other countries were mixed. In Russia, the study found women to be more strongly opposed to tax evasion, but only at the 11 percent level, which is generally considered insignificant. Even though, the study found the difference in gender to be insignificant in Brazil, men were significantly more opposed to tax evasion in the categories of incomplete secondary, technical and university degree. The study found the same degree of opposition to tax evasion for men and women in Germany except in the case of those who held a university degree where men were significantly more strongly opposed to tax evasion.

\section{Age and tax evasion}

Asante and Baba [2] looked at the effects of demographic matters on tax compliance among the self-employed in Ghana. They used a survey strategy and sampled 350 self-employed from Tema Metropolitan Assembly (TMA) using simple random sampling technique. Their data collection tool was a questionnaire made up of close-ended likert type scale items. In all, 267 self-employed were used in their analysis (giving a response rate of about $76 \%$ ). They examined the validity and reliability of their survey instrument by pre-testing and modification method. The estimated Cronbach alpha reliability coefficients found in favour of their study were 0.96 and 0.77 for the individual scales. The analysis of their result indicated that elderly self-employed people are less tax noncompliant than young self-employed.

Annan et al. [1] investigated into the factors that determine tax evasion in Ghana using time series data covering the periods 19702010. They employed the currency demand approach to estimate the level of tax evasion for the entire period. The analytical technique used by them was bounds test technique of cointegation. They measured age as a proportion of the Ghanaian population that fall in age category between 15 and 64. They found that younger taxpayers in Ghana are more risk lovers and less sensitive to sanctions.

A critical look at the above studies shows that age can be measured as a continuous variable or as categorical variable. Categorically, age is commonly grouped into a younger or an elderly person. Nevertheless, there is inconsistency in the measurement of a younger person. For instance, while Asante and Baba [2] defined a younger person as a person with "age category 18-39" and an elderly person as one with "age category 40 and above", Annan et al. [1] considered a younger person to be in the age "category between 15 and 64".

\section{Level of education and tax evasion}

Kriz et al. [10] employed micro-level data to determine the factors characterising individuals who evade payroll and income taxation in Estonia. They used log it estimation on three different cross-sectional datasets (Estonian Institute for Economic Research envelope wages survey, Taxes and Custom Board Audit and Labour Force Survey). Their three datasets broadly gave analogous results by indicating that payroll and income tax evasion is most prevalent among taxpayers who relatively have low level education. However, the result of their dataset one (EKI envelope wages survey) indicated an insignificant relationship between levels of education and payroll and income tax evasion.

Mcgee and Ross [9] found mixed results for the relationship between level of education and attitude toward tax evasion. They reviewed some prior studies on the ethics of tax evasion and also expatiated on the literature by examining the relationship between level of education and views on the ethics of tax evasion. They used Human Values data that was gathered by social scientists in Brazil, Russia, India, China, the USA and Germany and a 10-point Likert type scale. Their results showed that the group most opposed to tax evasion was the one in which participant had little or no formal education in Brazil, Russia and China, whilst the strongest opposition in India and the USA came from the most educated group. With regards to Germany the two groups 
tying for strongest opposition were those with incomplete elementary education and university degree. They found that one cannot say that the relationship between education and attitude toward tax evasion is uniform across countries and cultures.

\section{Tax audit, sanctions and tax evasion}

Several empirical studies show the effect of tax audit and use of sanctions on tax evasion. Devos [11] investigated into tax evasion behavior and demographic factors using exploratory method in Australia. That study particularly emphasised the relationship between taxpayers' knowledge of tax penalties and the effect of penalties on tax compliance decisions. The electronic survey questionnaire was used for the data collection. The data collected was analysed using the chisquare. A negative relationship between perceived severities of legal sanctions and tax compliance decisions was found after the analysis.

Asante and Baba [2] looked at enforcing tax compliance among the self-employed in the Accra Metropolis of Ghana. Using a sample 380 self-employed persons in the Accra Metropolis, they found a significantly positive correlation between sanctions and tax compliance. However, they observed that the effect of cooperation on tax compliance was larger than that of sanctions and so, they recommended that tax authorities should switch their approach to tax administration and possibly use sanctions as last resort.

Appah and Eze [12] examined the impact of tax audit on tax compliance in Nigeria. They collected data from both primary and secondary sources. While scholarly published and unpublished studies were used by them for collecting secondary data, structured questionnaire was used for collecting their primary data. Using a survey design, they randomly sampled Three hundred and sixty (360) respondents for the study. The analysis of their regression model revealed a significant relationship between tax audit and tax compliance.

\section{Perception about the importance of payment of tax and tax evasion}

Fagbemi, Uadiale and Noah [13] examined the relationship between culture (represented by legal enforcement, trust in government and religiosity) and personal income tax evasion in Nigeria. The study used survey design with a sample of Fifty (50) tax officials of the Lagos State Internal Revenue Service and One hundred (100) taxpayers in Lagos State. Using the chi square statistics and regression analysis, they found that trust in government has positive impact on personal income tax evasion.

Maseko [14] investigated the determinants of tax compliance in small and medium enterprises (SMEs) in Zimbabwe for the tax period 2009 to 2011. Data was collected using the structured interview and a survey questionnaire. It was found that the perceptions of SME operators about tax fairness, tax service quality and government spending priorities largely influence their tax compliance decisions. Adebisi and Gbegi [15] also examined the effect of tax avoidance and tax evasion on personal income tax administration in Nigeria. They sampled three hundred and five (305) employees of Federal Inland Revenue Service. Their datasets were both primary and secondary data. They also used tables and percentages and the Analysis of Variance (ANOVA) to test their hypotheses. The analysis of their results revealed that adequate utilization of tax revenue on public goods will discourage tax avoidance and tax evasion.

\section{Perception about the amount of tax (a proxy to tax rate) and tax evasion}

Razak and Adafula [16] studied the influence of attitudes of individual taxpayers on tax compliance decisions in Ghana. They surveyed responses from questionnaires administered to operators of SMEs in Tamale. Their descriptive and inferential analysis showed that individuals are much concerned with the amount of taxes they pay, the rates of income taxes, and the burden of taxes paid and these influence their decisions to pay tax. A similar result was found by Yalamaand Gumus [7] in Turkey. They found a positive relationship between tax evasion and taxation and fiscal factors (tax rate and tax burden). Thus, an increase in the tax rate and in the tax burden increases tax evasion.

The implication from the above empirical evidences is that it is likely for taxpayers who perceive the amount of tax stamps to be high to evade tax stamp. Therefore a positive expectation is formed for perception about the amount of tax and the tax stamp evasion.

\section{Guilt feeling and tax evasion}

Erard and Feinstein [17] looked at the role of moral sentiments and audit perceptions in tax compliance in the U.S. Their aim was to extend the expected utility model through the inclusion of guilt and shame in the model. Their dataset comprised detailed tax and audit information from the state of Oregon and the U.S Internal revenue Service. Seven hundred and sixteen (716) tax filers were sampled for the study. Using the binary $\log$ it, they found that when taxpayers' perceptions are constrained to the realistic levels, guilt and shame become important determinants of compliance behaviour.

Benk et al. [18] applied the theory of planned behavior to the study of tax compliance intention in the city of Zonguldak in Turkey. The main objective was to examine the extent to which perceived tax equity (vertical, horizontal and exchange), normative expectation (social and moral norms) and legal sanctions (detection risk and penalty magnitude) affect tax compliance intentions. 369 successfully completed survey questionnaires were used for the analysis. The authors measured social norms using two constructs (influence of family and friends) on a 5-point scale. They also used two constructs to measure moral norms (guilt feeling and personal principles). Using the Ordinary Least Square regression, they found a positive correlation between moral norms, social norms and tax compliance.

\section{Belonging to association and tax evasion}

Alm et al. [19] carried out an experiment on information provision and dissemination. They grouped their study into three sessions. Session one was the base case session where participants received no information about audit results beyond their own audit experience. Session two was the session in which the same objective audit rates were in effect but the participants had additional information in the form of the actual number of audits conducted and the fines collected during a period. The third session was the session in which the participants were given options to send a "message" to the other participants about their audit experience. It was found that when unofficial messages from other taxpayers report higher levels of compliance among taxpayers, individuals are more likely to comply in subsequent round while compliance decreases when messages are consistent with widespread evasion.

Alm et al. [20] also carried out a similar experiment and found a similar result. They examined the effect of information dissemination on tax compliance using experimental design and found that taxpayers 
are more likely to file and to report their taxes when they get to know that their colleagues are also filing and reporting their taxes. Consequently, taxpayers are more likely to evade when they believe that others are also cheating on their taxes. Andriani [21] also looked at the effect of public spirit and associational activity on Palestinians' tax morale-intrinsic motivation to pay taxes. They used dataset based on a survey conducted by the Palestine Economic Policy Research Institute in 2007 in the West Bank and Gaza Strip. They run a bivariate probit model and found that tax morale is lower among Palestinians involved in associational activities.

\section{Methodology}

The survey method was adopted for this study using the interview schedules as the main data collection instrument for all micro business owners who are obliged to buy tax stamps. In addition to questions on the main issues in the study, the instruments contained items that were designed to collect data on the socio-economic background of the taxpayers.

\section{Study area}

The 2010 population and housing census report shows that the age distribution of age group 0-4 years exhibits the highest proportion of 14.9 percent and the age group of $85+$ years constitutes the lowest proportion of 0.5 percent. With regards to sex ratio, usually expressed as the number of males for every 100 females, the sex ratio of the district is 97.4 which imply that there are 97.4 males to every 100 females in the district. The sex ratio of the district is higher than the regional ratio of 91.2 , indicating that females are more than males. At the active working stage (55-59 years) the sex ratio is 113.2 [22].

About 73.0 percent of the total population (aged 15 years and above) is economically active while 27.0 percent are economically not active. Of the economically active population, 97.2 percent are employed while 2.8 percent are unemployed. The peak of employment status is between ages 40-44 years for both sexes. The employed population of 15 years and above has 67.5 percent as self-employed without employees while 2.8 percent are self-employed with employees. Casual workers are 1.9 percent. Majority of the people are engaged in petty trading activities, especially females who represent about $69.5 \%$ of the selfemployed without employees. The private informal sector is the largest employer in the district, employing 89.7 percent of the population. This is followed by the public sector with 6.3 percent [22].

\section{Target population}

The target population comprised taxpayers in the study area who qualify for tax stamp purchases. They include persons operating in kiosks, identifiable groups such as, hairdressers, dressmakers and tailors, butchers, market traders, chop bar and cooked food sellers, artisans such as, masons, carpenters, welders, and technicians. These categories of taxpayers form part of the self-employed in the informal sector.

\section{Sample Size determination}

The target population for this study (tax stamp cases) represents a portion of the population of self-employed in the study area. The 2010 Population and Housing Census pegs self-employed in the study area at 33741. Hence, with a given level of confidence as well as error of margin, the minimum sample size according to Cochran [5] was determined proportionately as:
Where: $\quad n=\frac{\rho q z^{2}}{E^{2}}$

$\rho$ is the percentage belonging to the specified category, based on assumed population proportion, existing information or pilot studies,

$\mathrm{q}$ is $1-\rho$, the percentage not belonging to the specified category,

$z$ is the $z$-value corresponding to the level of confidence required, and

$E$ is the margin of error required.

$\rho=0.5$ for unknown population size

Since the sampling frame for tax stamp cases is unknown in the study area, $\rho$ is considered to be 0.5 . Taken $95 \%$ as the level of confidence, $5 \%$ margin of error and a $\mathrm{z}$-value of 1.96 , the minimum sample size were calculated as:

$$
n=\frac{0.5(0.5)(1.96)(1.96)}{0.05(0.05)}=384 \text { Taxpayers }
$$

\section{Sample and sampling technique}

This study was designed to obtain data from taxpayers who qualify for tax stamp purchases in the Twifo Atti-Morkwa Sub Tax District. The study area consists of four Paramount: Twifo, Atti-Morkwa, Hemang and Lower Denkyira. Considering the nature of the study area, three sampling techniques were used. Stratified sampling was first used to divide the study area into four strata with each stratum representing a paramount. Simple random sampling technique was used to select a community from each of the stratum. In all, four communities were selected: Praso, Agona, Hemang and Jukwa.

In order to obtain the sample size as computed, a quota was assigned to each of the selected communities. The quota was based on the premise that a sample will represent the population, as the variability in a sample for various quota variables is the same as those in the population [23]. The calculation of quotas was based on relevant data that was usually relative to the proportions in which they occur in the population. Nevertheless, such criteria vary as a range of factors including the nature and type of research play a major role [24-26]. Hence, quotas were assigned to the communities based on population density of the community.

The simple random technique was also used to actually select the members into the sample. In each community, one out of every two tax stamp cases was selected. The process was repeated until the suitable sample was drawn. This approach was adopted to give each and every taxpayer an equal opportunity to be selected, as well as ensure the possibility of making generalisation about the population [27-30].

\section{Estimation technique}

As indicated in the introduction, the negative binomial regression technique was adopted for this study. A random variable $\mathrm{X}$ is negative binomial distributed if its probability distribution function is given by:

$$
\operatorname{Pr}(Y=y \mid \mu, \alpha)=\frac{\Gamma\left(\alpha^{-1}+y\right)}{\Gamma\left(\alpha^{-1}\right) \Gamma(y+1)}\left\{\frac{\alpha^{-1}}{\alpha^{-1}+\mu}\right\}^{\alpha^{-1}}\left\{\frac{\mu}{\mu+\alpha^{-1}}\right\}^{y}
$$

Where $\Gamma($.) denotes the gamma integral that specialises a factorial for an integer argument. Given sample data, the corresponding loglikelihood function is the logarithm of the product of the marginal probabilities as in the following:

$$
\sum_{i=1}^{N} \frac{y_{i}-\mu_{i}}{1+\alpha \mu_{i}} X_{i}=0
$$




$$
\sum_{i=1}^{N}\left[\frac{1}{\alpha^{2}}\left\{\operatorname{In}\left(1+\alpha \mu_{i}\right)-\sum_{j=0}^{y_{i}-1} \frac{1}{j+\alpha^{-1}}\right\}+\frac{y_{i}-\mu_{i}}{\alpha\left(1+\alpha \mu_{i}\right.}\right]=0
$$

The negative binomial maximum likelihood estimator is that value which maximizes this log likelihood function.

\section{Empirical model}

$$
\begin{aligned}
& \operatorname{Pr}(Y=y \mid \mu, \alpha)=\beta_{0}+\beta_{1} \text { gender }+\beta_{2} \text { age }+\beta_{3} \text { educ }+\beta_{4} \text { taxaud }+\beta_{5} \text { san }+ \\
& \beta_{6} \text { import }+\beta_{7} \text { amtax }+\beta_{8} \text { guilt }+\beta_{9} \text { dist }+\beta_{10} \text { assoc }+\beta_{11} \text { inc }+\varepsilon_{i}
\end{aligned}
$$

Where: gender=gender of the taxpayer, age=age of the taxpayer, educ=level of education of the taxpayer, taxaud=frequency of tax audit, San=application of sanctions, import=taxpayers perception about the importance of payment of tax, amtax=perception of the taxpayer about the amount of tax, guilt=guilt feeling, dist=distance to the tax office, assoc=belonging to micro business association, inc=level of income earned by the taxpayer and $\varepsilon=$ stochastic error term.

The stochastic error term was included in the empirical model to introduce all the changes in $\mathrm{Y}_{\mathrm{i}}$ that cannot be predicted by the included predictor variables. It is a symbol which takes care of the inability to model all the movements of the dependent variable $\left(\mathrm{Y}_{\mathrm{i}}\right)$. This is so because it is possible that there may be errors in the specification of the model, omitted variable biases and errors in data measurement. The stochastic error term caters for all these errors. The independent variables used in the model were selected based on the theoretical and empirical review.

\section{Result and Discussions}

In all, 305 interview schedules were successfully completed by the respondents. This represented a response rate of 79.42 percent. The distribution of respondents according to gender is presented in Table $1227(74.43 \%)$ taxpayers in the informal sector were females while 78 (25.57\%) were males. The results confirm the submission by that over $80 \%$ of the informal operators in Ghana are women.

Profiled by age, it was found that the oldest respondent was 64 years while the youngest was 19 years. The mean age of the taxpayers was approximately 34 years with the associated standard deviation being 9.1664. Majority of the respondents were between the ages 27 and 34 . The least number of respondents however, were found in the age 51 and above. The distribution is presented in Table 2. As there are many young taxpayers in the district, it is likely that there would be more tax noncompliance in the district. This conclusion follows Asante and Baba's [2] submission that elderly self-employed people are less tax noncompliant than young self-employed. It also corroborates the findings of Annan, Bekoe and Nketiah-Amponsah [1] that younger taxpayers in Ghana are more risk lovers and less sensitive to tax sanctions.

The academic qualification of the respondents was also important for the study. Out of the 305 respondents used for the study, 16 (5.24\%) had no formal education, 203 (66.56\%) had attended the Basic School, 67 (21.97\%) had attended Senior High/Vocational/Technical, whilst 19 (6.23\%) had obtained Tertiary level education (Colleges of education, Polytechnic and University). The distribution according to academic qualification implies that most of the taxpayers in the district have low level education. About 219 of the participants had either no formal education or the basic school education. This result indicates that there is likely to be more tax evasion among taxpayers in the informal sector. This conclusion is based on Kriz et al. [10] submission that tax evasion is most prevalent among taxpayers who relatively have low level education. It also finds support in Mcgee and Ross's [9] finding that in India and the USA, the strongest opposition to tax evasion came from the most educated group (Table 3 ).

The study used equation (3) to estimate factors that influence tax stamp purchases in the study area. The negative binomial regression equation in the previous section was estimated to determine factors that explain the expected log count of number of tax stamp purchased in the study area. The outcome of these analyses is provided in Table 4.

In Table 4 , the Wald chi-square is significant at 0.01 percent level of significance $(\mathrm{P}$-value $=0.000)$ indicating that the combined independent variables significantly explain the dependent variable (number of tax stamp purchased). Also, the table shows the log-transformed overdispersion parameter (/lnalpha) and its corresponding estimated untransformed value. A Poisson model is one in which this alpha value is constrained to zero. Stata finds the maximum likelihood estimate of the log of alpha and then calculates alpha from this. This means that alpha is always greater than zero and that negative binomial only allows for over dispersion (variance greater than the mean). The likelihood ratio test in Table 4 compares the negative binomial model to a Poisson model and the associated chi-squared value is 109.66 with one degree of freedom. This means that alpha is non-zero and the negative binomial model is more appropriate than the Poisson model. Therefore, the authors went ahead to explain the negative binomial regression results.

The study found that factors that explain the expected log count of number of tax stamp purchased in the study area were the level of taxpayer's education, perception about the importance of tax payment, distance to be covered before getting to the tax office, the level of income of the taxpayer, tax audit, application of sanctions and guilt feelings as presented in Table 4.

The taxpayer's level of education was captured by three indicator variables, setting no formal education as the reference category. Only tertiary education was significant at $10 \%$. The expected log count for a taxpayer with tertiary education was 0.669 higher than the expected $\log$ count for a taxpayer with no formal education. This means that a

\begin{tabular}{|c|c|c|}
\hline Gender & Frequency & Percentage \\
\hline Female & 227 & 74.43 \\
\hline Male & 78 & 25.57 \\
\hline Total & 305 & 100.00 \\
\hline
\end{tabular}

Table 1: Distribution of taxpayers in the informal sector by gender.

\begin{tabular}{|c|c|c|}
\hline Age & Frequency & Percentage \\
\hline $19-26$ & 63 & 20.66 \\
\hline $27-34$ & 113 & 37.05 \\
\hline $35-42$ & 80 & 26.23 \\
\hline $43-50$ & 30 & 9.84 \\
\hline 51 and above & 19 & 6.23 \\
\hline Total & 305 & 100.00 \\
\hline
\end{tabular}

Table 2: Age distribution of the respondents.

\begin{tabular}{|c|c|c|}
\hline Academic qualification & Frequency & Percentage \\
\hline No formal education & 16 & 5.24 \\
\hline Basic School & 203 & 66.56 \\
\hline SHS/Noc/Tech & 67 & 21.97 \\
\hline Tertiary level education & 19 & 6.23 \\
\hline Total & 305 & 100.00 \\
\hline
\end{tabular}

Table 3: Distribution of respondents according to academic qualification. 


\begin{tabular}{|c|c|c|c|c|c|c|}
\hline Variable & Coefficient & STD Err & $\mathbf{Z}$ & $P>Z$ & 95\% Conf. & Internal \\
\hline Gender & 0.0681269 & 0.2204034 & 0.31 & 0.757 & -0.3638559 & 0.5001096 \\
\hline Age & -0.0172481 & 0.0108212 & -1.59 & 0.111 & -0.0384573 & 0.003961 \\
\hline \multicolumn{7}{|l|}{ Education } \\
\hline Basic & -0.3461408 & 0.3338288 & -1.04 & 0.300 & -1.000433 & 0.3081516 \\
\hline Secondary & -0.1768927 & 0.4180935 & -0.42 & 0.672 & -0.9963409 & 0.6425556 \\
\hline Tertiary & 0.669909 & 0.3843089 & 1.74 & 0.081 & -0.0833226 & $1.423141^{*}$ \\
\hline Importance & 0.6564535 & 0.2049983 & 3.20 & 0.001 & 0.2546643 & $1.058243^{*+* t}$ \\
\hline \multicolumn{7}{|l|}{ Amount of Tax } \\
\hline Moderate & -0.8578295 & 0.7602766 & -1.13 & 0.259 & -2.347944 & 0.6322852 \\
\hline High & -1.130752 & 0.7311713 & -1.55 & 0.122 & -2.563821 & 0.3023177 \\
\hline Distance & -0.0151467 & 0.0064644 & -2.34 & 0.019 & -0.0278166 & $-0.0024767^{* *}$ \\
\hline \multicolumn{7}{|l|}{ Income } \\
\hline GHS 50-145 & 0.845508 & 0.2285607 & 3.70 & 0.000 & 0.3975372 & $1.293479^{* * *}$ \\
\hline Above GHS145 & 0.846277 & 0.2681941 & 3.16 & 0.002 & 0.3206263 & $1.371928^{* * * *}$ \\
\hline Tax Audit & 0.3948572 & 0.0926494 & 4.26 & 0.000 & 0.2132676 & $0.5764467^{* * *}$ \\
\hline Sanction & 0.8477766 & 0.266329 & 3.18 & 0.001 & 0.3257814 & $1.369772^{* * *}$ \\
\hline Association & -0.0436939 & 0.2125051 & -0.21 & 0.837 & -0.4601964 & 0.3728085 \\
\hline Guilt feeling & 0.3733166 & 0.2120675 & 1.76 & 0.078 & -0.042328 & $0.7889612^{* *}$ \\
\hline _cons & 0.8422374 & 0.8834094 & 0.95 & 0.340 & -0.8892132 & 2.573688 \\
\hline /Inalpha & 0.621819 & 0.1903889 & & & 0.2486637 & 0.9949743 \\
\hline alpha & 1.862312 & 0.3545635 & & & 1.282311 & 2.704655 \\
\hline
\end{tabular}

Number of observation $=305$, Pseudo $R^{2}=0.0738$.

Dispersion=Mean, Wald $\mathrm{chi}^{2}(15)=0.10134$.

Log Pseudolikelihood=-386.1686, Prob $>\mathrm{Chi}^{2} 0.0000$

Likelihood-ratio test of alpha $=0$ : chibar2 $(01)=109.66, \mathrm{Prob}>\mathrm{chi}^{2} 0.000$.

${ }^{*} \mathrm{P}>\mathrm{Z}=0.1{ }^{* *} \mathrm{P}>\mathrm{Z}=0.05 ;{ }^{* * *} \mathrm{P}>\mathrm{Z}=0.01$.

Table 4: Negative binomial regression analysis on number of tax stamp purchased.

taxpayer with tertiary education is more likely to buy more tax stamp as compared to taxpayer who has no formal education. This can be attributed to the fact that a taxpayer with tertiary education knows the role tax plays in the development of a country and therefore sees paying of tax as an obligation. These results confirm the findings of Mcgee and Ross [9] that showed that the strongest opposition to tax evasion in India and the USA came from the most educated group. They also confirm the findings of Kriz et al. [10] that income tax evasion is most prevalent among taxpayers who relatively have low level education.

The coefficient of perception about the importance of tax payment was 0.656 . This was significant at $0.01(\mathrm{P}>\mathrm{Z}=0.001)$. The expected $\log$ count for a taxpayer who perceives payment of tax as important was 0.656 higher than the expected log count for a taxpayer who does not perceive tax payment as being important. Thus, a taxpayer who perceives payment of tax as important is more likely to buy more tax stamps as compared to a taxpayer who does not perceive tax payment as important. These results corroborate the findings of Fagbemi et al. [13] that the importance attached to tax payment as measured by perceptions of tax fairness, tax service quality and government spending priorities has positive impact on personal income tax evasion.

The variable distance was significant in determining the number of tax stamps purchased. Distance as a variable had a coefficient of -0.0151467 and was statistically significant at 0.05 level of significance $(\mathrm{P}>\mathrm{Z}=0.019)$. This means that for one kilometer increase in distance to a revenue collection centre, the expected log count of tax stamp purchased decreases by 0.0151467 . The implication is that the nearer the distance of revenue collection center, the more likely the taxpayer will increase the number of tax stamps purchased.

The taxpayer's level of income was also considered in this study. Income was categorised into three. The researcher used those who earn income below GHS 50 as a reference category. The indicator variable "GHS 50-145" was the expected difference in log count between taxpayers who earn monthly income within category "GHS 50-145" and the reference category (monthly income below GHS 50 ). The expected log count for "GHS 50-145" of income was 0.845 higher than the expected log count for the reference category. The indicator variable " $>$ GHS 145 " is the expected difference in log count between group "> GHS 145 " and the base category "monthly income below GHS 50". The expected log count for "> GHS 145" of income was 0.846 higher than the expected log count for the base category. This means that income has positive correlation with number of tax stamp purchased. The greater the level of income, the greater the urge to purchase stamp tax.

Rate of tax audit has a coefficient of 0.3948 and it was statistically significant at 0.01 level of significance $(P>Z=0.000)$. This means that for one-unit increase on rate of tax audit, the expected log count of the number of tax stamp purchased increases by 0.3948 . Application of sanctions was statistically significant at 1 percent level. The coefficient of application of sanctions was 0.8477 . The expected log count for a taxpayer whose shop has been locked before was 0.8477 higher than the expected log count for a taxpayer whose shop has not been locked before. This means that a taxpayer whose shop has been locked before is more likely to buy more tax stamps as compared to a taxpayer whose shop has not been locked before. This result is consistent with the findings of Asante and Baba [2] that the more a tax evader is sanctioned, the more he or she is discouraged from tax evasion. The above result also corroborates the findings of Devos [11] that there is a negative relationship between perceived severities of legal sanctions and tax compliance decisions.

Guilt feeling is another variable that was considered relevant for this study. The factor was significant at 0.1 level of significance $(\mathrm{P}>\mathrm{Z}=0.078)$. It has a coefficient of 0.373 . The expected log count for a 
taxpayer who feels discomforted when caught for not buying tax stamp is 0.373 higher than the expected log count for a taxpayer who will not feel the same. The result of guilt feeling variable is consistent with the findings of Benk et al. [18] that when taxpayers' perceptions are constrained to the realistic levels, guilt and shame become important determinants of compliance behaviour. The result is also consistent with the conclusions drawn by Erard and Feinstein [17] that a moral individual who does not pay tax incurs a psychic cost (guilt feeling) and becomes happy when he or she fully complies with tax laws.

\section{Conclusion and Recommendation}

Based on the findings of the study, it can be concluded that the expected log count of the number of tax stamp purchased per year in the study area are explained by the level of education, perception about the importance of tax payment, application of sanctions, guilt feelings, tax audit and distance to tax office. However, among these determinants, the application of sanctions, income of the taxpayer, educational attainment, and perception about the importance of tax payment had greater effects on the expected log count of the number of tax stamp purchased per year. Although, guilt feelings, tax audit and distance to tax office were also significant, they had less effect on the expected log count of the number of tax stamp purchased per year in the study area. On this basis, it is recommended that while there are many determinants of the number of tax stamp purchased per year by micro-business owners in Ghana, policy makers must focus on the most significant determinants in order to reduce tax evasion and improve the tax revenue in Ghana. The Ghana Revenue Authority is encouraged to apply sanctions promptly when tax auditors catch some tax stamp defaulters and also Tax auditors should go round at least at the beginning of every quarter to inspect the number of tax stamps that taxpayers have bought.

\section{References}

1. Annan B, Bekoe W, Nketiah-Amponsah E (2013) Determinants of tax evasion in Ghana: 1970-2010. International Journal of Economic Sciences and Applied Research 6: 97-121.

2. Asante S, Baba SA (2011) Tax compliance among self-employed in Ghana: Do demographic characteristics matter. International Business and Management 3: $86-91$.

3. Terkper S (2013) Ghana's energy crisis to impede 2013 domestic revenue mobilisation.

4. Amponsah S, Adu KO (2015) Factors in uencing tax stamp purchases in Ghana: A case of Twifo-Atti Morkwa sub-tax District.

5. Cochran WG (1977) Sampling techniques. (3rdedn), John Wiley \& Sons, New York.

6. Venter VH (2011) Factors influencing tax evasion.

7. Yalama OG, Gumus E (2013) Determinants of tax evasion behavior: Empirical evidence from survey data. International Business and Management 6: 15-23.

8. Kedir MA, Fethi DM, and Williams CC (2011). Evaluating tax evasion in the European Union: A case study of the prevalence and character of 'envelope wage' payments. University of Leicester. Department of Economics, Working paper No.11/13.

9. McGe RW, Ross AM (2014) Educational level and ethical attitude toward tax evasion: A six-country study.
10. Kriz KA, Merikull J, Paulus A, Staehr K (2007) Why do individuals evade payroll and income taxation in Estonia.

11. Devos K (2014) Tax compliance theory and literature.

12. Appah E, Eze G (2013) A causality analysis between tax audit and tax compliance in Nigeria. European Journal of Business and Management 5: 107120

13. Fagbemi OT, Uadiale MO, Noah OA (2010) The ethics of tax evasion: Perceptual evidence from Nigeria. European Journal of Social Sciences 17 360-371.

14. Maseko N (2013) Determinants of tax compliance in small and medium enterprises in Zimbabwe.

15. Adebisi JF, Gbegi DO (2013) Effect of tax avoidance and tax evasion on personal income tax administration in Nigeria. American Journal of Humanities and Social Sciences 1: 125-134.

16. Razak A, Adafula JC (2013) Evaluating taxpayers' attitude and its influence on tax compliance decisions in Tamale. Journal of Accounting and Taxation 5: $48-57$

17. Erard B, Feinstein SJ (1994) The role of moral sentiments and audit perceptions in tax compliance. PUB. FIN. 70: 74-76.

18. Benk S, Çakmak AF, Budak T (2011) An investigation of tax compliance intention: A theory of planned behavior approach. European Journal of Economics, Finance and Administrative Sciences 28: 181-188.

19. Alm J, Jackson RB, Mckee M (2004) Audit information dissemination, taxpayer communication and tax compliance: An experimental investigation of indirect audit effects. National Tax Association.

20. Alm J, Bloomquist MK, Mckee M (2012) Getting the word out: Increased enforcement, audit information dissemination and compliance behavior. j. jpubeco. 93: 392-402.

21. Andriani L (2012) Tax morale and pro-social behavior: Evidence from a Palestinian survey. Camb. J. Econ.

22. Ghana Statistical Service (2014) 2010 population and census report: District analytical report.

23. Saunders M, Lewis $P$, Thornhill A (2012) Research methods for business students. (6thedn), Pearson Education Limited, England.

24. Akerlof AG, Kranton RE (2010) Identity economics. Princeton University Press, New Jersey.

25. Amoah T P (2012) Small business owners' attitude towards tax stamp: A case study of taxpayers in Sekondi.

26. Armah-Attoh D, Awal M (2013) Tax Administration in Ghana: The perceived institutional challenges.

27. Baba SA (2010) Enforcing income tax compliance among the self-employed in the Tema Metropolis of Ghana.

28. Ghana Revenue Authority (2012) A guide to tax stamp.

29. Ghana Statistical Service (2012) 2010 population and census report.

30. Internal Revenue Act (2000) (Act 592). 